\title{
The Relationship Between Brand Positioning and Packaging Color of Chocolate
}

\author{
Jie $\mathrm{Du}$ \\ School of Art \& Design \\ Xi'an University of Technology \\ Xi'an, China 710048
}

\author{
Yawen Wang \\ School of Art \& Design \\ Xi'an University of Technology 710048 \\ Xi'an, China 710048
}

\begin{abstract}
Chocolate is one of the most popular candy products for consumers. The color bias of chocolate packaging design will directly affect consumers' perception of chocolate brands. In the design of modern chocolate packaging color, correctly finding the relationship between the color elements of the chocolate packaging and the brand image, making specific analysis and applying the color matching the brand image to the packaging has a certain effect on the establishment of the enterprise brand and the marketing of the product.
\end{abstract}

\section{Keywords—chocolate; packaging color; brand building}

\section{INTRODUCTION}

The positioning of the chocolate brand determines its marketing selling point. According to the positioning of its own brand, the designer selects the reasonable color and makes the targeted color matching to make packaging color have a strong visual impact, so that people will feel happy and further produce sensory satisfaction, which trigger emotional resonance, and stimulate consumers' desire to purchase [1]. At present, the chocolate packaging design in the domestic market lacks the color style of the brand, and the color performance of the packaging design is too single, which leads to the aesthetic fatigue of consumer and can't reflect the inheritance of the brand itself. It is difficult for the serial packaging to form a sense of brand identity, and the classification of the brand function is not clear, which is easy to mislead consumers. The problems arising from these packaging design processes will greatly restrict the development of domestic chocolate brands, and make the sales and display visual effects of chocolate products is bad situation, which is not good for domestic chocolate products to compete with international brands in the future chocolate industry.

Therefore, the success of the chocolate brand's packaging color is related to the success of brand competition and sales of chocolate. Two factors should be considered in designing packaging colors of Chocolate brands. First, we should determine the market positioning of the chocolate brand, the level it belongs to, and the type of consumer group it will attract. Second, we should determine the psychological characteristics, hobbies, lifestyles and other related information of the consumer group, to attract consumers' attention through color firstly in addition to the product name. Colors such as reddish brown and coffee color used in chocolate packaging on the market are easy for consumers to recognize and understand. They have been considered as the indispensable colors in chocolate packaging. We can use these colors to lay the tone of chocolate packaging color, and then convey its taste through specific graphics and color matching to guide the consumer's visual process.

\section{ANALYSIS OF CHOCOLATE PACKAGING COLOR}

Taking the popular Dove, Hershey, and Jindi chocolates on the market as examples, they have both fixed chocolate packaging colors and unique brand colors in their packaging color design, which is well combined with their brand image and product positioning. It has laid a good foundation for subsequent product marketing and made it a popular chocolate brand. The design of packaging color under the brand positioning height is a bridge to establish communication between brands and consumers. Dove brand has positioned itself in the middle and high-end market, maintained the characteristics of chocolate as a token of love representing romance to attract young white-collar women with price strategy. The Hershey brand has positioned itself in the middle and high-end market. Its advertising mainly highlights the fact that although the chocolate is small, it tastes good and the main target audience is children. The Jindi will position itself in the low-end market and attract grassroots consumers with high cost performance.

In view of the brand image and market positioning of Dove, Hershey and Jindi, this research explores the rules and functions of the packaging color of these three brands through the analysis of their packaging color data. Exploring the correlation between chocolate brands and packaging color design provides a valuable reference for other brands to design packaging colors and establish corporate image.

This study selects chocolate brands such as Dove, Haoshi and Jindi, which have good brand reputation in the market as research samples, see "Table I".

TABLE I. CHOCOLATE BRAND SAMPLE

\begin{tabular}{|l|l|l|l|}
\hline $\begin{array}{c}\text { Brand } \\
\text { Name }\end{array}$ & $\begin{array}{c}\text { Sample } \\
\text { Quantity }\end{array}$ & \multicolumn{1}{c|}{ Origin } & Manufacturer \\
\hline Dove & 10 & Beijing, Jiaxing & Mars Inc \\
\hline Hershey & 7 & Shanghai & Hershey \\
\hline Jindi & 7 & Shenzhen & COFCO Jindi Food \\
\hline
\end{tabular}


In this study, the front view of the chocolate package was taken as the research object, and they were divided into equal square areas. Samples were taken at the intersection of the horizontal and vertical axes. Due to different package size of each sample, the number of samples was also different. The $\mathrm{L}$ and $\mathrm{C}$ values of the samples ( $\mathrm{L}$ for lightness and $\mathrm{C}$ for saturation) are extracted by the color picker tool in Photoshop software [2]. Through the data of lightness value and saturation value, the brightness and saturation of the packaging color matching of the three major chocolate brands (Dove, Hershey, and Jindi) were analyzed.

\section{A. Scatter L-C Distribution of Package Color}

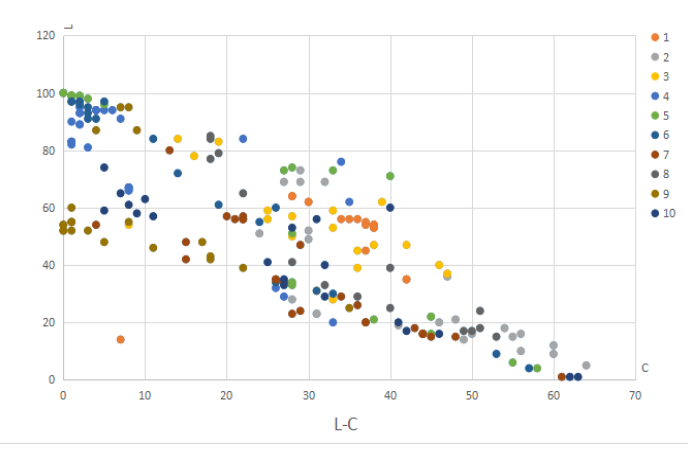

Fig. 1. Dove chocolate scatter L-C distribution.

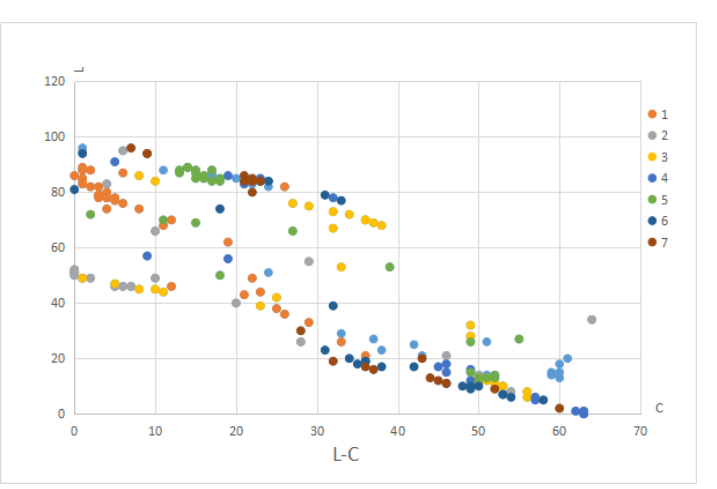

Fig. 2. Hershey's Chocolate scatter L-C distribution.

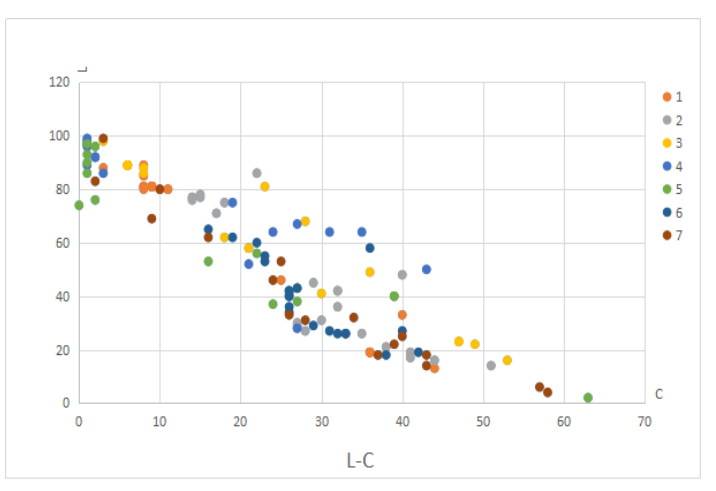

Fig. 3. Leconle Chocolate scatter L-C distribution.

The L-C value scatter plot of the front view of the Dove chocolate package (including graphic color, text color, and background color, etc.) can be seen.
- Lightness: Among the total 229 samples, 174 samples (about $76.0 \%$ of all samples) have $\mathrm{L}$ values greater than 30, indicating that the color brightness of Dove packaging is not low; among the 140 samples of sample 1, sample 3, sample 4, sample 5, and sample, $107(76.4 \%)$ had $\mathrm{L}$ values between 50 and 100 . Sample 2, sample 7, sample 8, and sample 10 have lower L values, and of the 89 samples, 50 samples (about 56.2\%) have L values below 40, with low color brightness.

- Saturation: Of the total 229 samples, 185 (about $80.8 \%$ of all samples) have C values below 40, indicating that the color saturation used in Dove chocolate packaging was generally low. Sample 1, Sample 2, Sample 6, and Sample 9 have C values below 10, and of the 102 samples, 68 samples (about $66.7 \%$ ) have low saturation.

Sample 4, Sample 5, and Sample 6 overlap with the above three samples of high brightness. These three flavors of chocolate packaging have chosen the highlightness, low-saturation color as the background color, and then use a small amount of low-lightness, high-saturation color as a match to highlight the difference in taste, so that consumers can see clearly the difference in taste at a glance.

It can be seen from the scatter plot of the L-C value of the front view (including graphic color, text color, background color, etc.) of the Hershey chocolate package in "Fig. 2".

- Lightness: Of the total 178 samples, 113 (about $63.5 \%$ of all samples) had an $\mathrm{L}$ value higher than 40 , indicating that the color brightness of the package was generally higher. Among them, 57 of the 92 samples of sample 1, sample 3, and sample 5 (about $62.0 \%$ ) had an $\mathrm{L}$ value higher than 70 . Two of the three samples are almond milk chocolate, which uses high lightness yellow as the main color, with a small amount of reddish brown as decoration to reflect the health of the nutty chocolate. The color of same taste shows serialization. Of the 18 samples of sample 4, 11 (about $61.1 \%$ ) had an $\mathrm{L}$ value less than 40 , which means the color brightness is low and it is consistent with the inherent color of white chocolate.

- Saturation: Of the total 178 samples, 127 (about $71.3 \%$ of all samples) had C values below 40, indicating that the color saturation used in Hershey chocolate packaging was generally low. The $\mathrm{C}$ value of sample 1 and sample 2 was low, and of the 59 samples, that of 37 samples (about 62.7\%) were lower than 10, which means the saturation was low. Of the 48 samples of Sample 3 and Sample 4, 31 (about $64.6 \%$ ) were in $30-60$, so the saturation is moderate.

It can be seen from the scatter plot of the L-C value of the front view of the Jindi chocolate package (including graphic color, text color, background color, etc.). 
- Lightness: Of the total 138 samples, 80 of them (about $58.0 \%$ of all samples) had $\mathrm{L}$ values concentrated at $0-40$, indicating that the color of the Jindi packaging is low. Among them, 24 of the 40 samples of sample 1 and sample $5(60.0 \%)$ had an L value higher than 70 . The packaging color of these two samples uses a large area of gold or golden yellow as the background color, which improves the brightness of the overall package. Of the 41 samples of sample 2 and sample 7, 22 samples (about 53.7\%) had an L value less than 40, which shows a low color brightness.

- Saturation: Of the total 138 samples, 117 (about $84.8 \%$ of all samples) had a $\mathrm{C}$ value less than 40 , indicating that the color saturation used by Jindi chocolate packaging was generally low. Of the 24 samples of sample 1, 14 (about 58.3\%) had $\mathrm{C}$ values below 10, showing low saturation. Among the 62 samples of sample 2, sample 6, and sample 7, 49 samples (about $79.0 \%$ ) had $\mathrm{C}$ values concentrated at 20-60, so the saturation was moderate.

\section{B. The Average Color of Chocolate Packaging Color}

The averaging function under the Filter menu to get the average color of the front of the chocolate package is used as a benchmark.

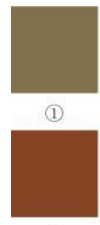

(6)

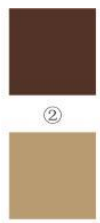

(7)

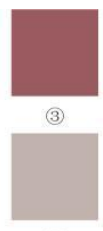

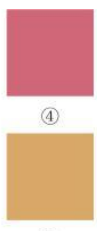

(9)

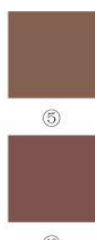

Fig. 4. Average of Doves' packaging.
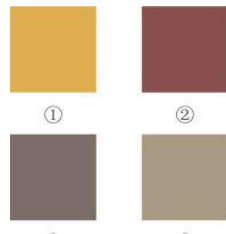

(4)

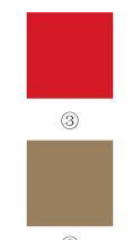

(6)

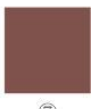

Fig. 5. Average of Hershey's packaging.
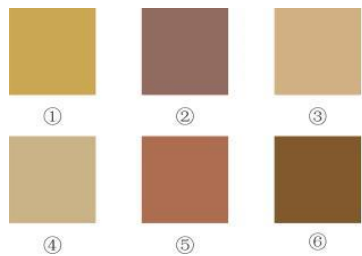

(6)

Fig. 6. Average of Leconle's packaging.

As can be seen from the average color of the Dove packaging in "Fig. 4", Dove's packaging color selection tends to be the red series, which is consistent with the romantic and emotional positioning of the Dove brand. This is the feature that other chocolate brands don't have or don't clearly pointed out, which forms a difference point with other chocolate brands, makes up for the market gap, and makes it easier to obtain consumers' favor and strengthen their brand loyalty.

It can be seen from the average color of the Hershey packaging in "Fig 5" that the packaging color selection of Hershey is more abundant. Hershey's own brand strategy is the mid-to-high end market. There are also bright colors in the color design of Hershey's packaging. White, gold, and red gives people a warm feeling in color, showing their unique brand personality charm, which distinguishes it from other chocolate brand packaging, and changes the public impression of chocolate packaging — reddish brown packaging. This bright, flesh color combination is easy to identify and is more attractive, which can stimulate sales of the company's products, and is suitable for the positioning of the Hershey brand.

It can be seen from the average color of the Jindi packaging in "Fig. 6", the packaging color of Jindi is more monotonous with strong seriation. Abandoning a large area of reddish brown, it chooses the light yellow with low light and low saturation. The color is warm and elegant and meets its rich and thick characteristics. The positioning of Jindi chocolate is the low-end market, and the price is acceptable and enjoyable by the public. Therefore, the color it chooses gives people a sense of intimacy, which is consistent with the fact that the brand conveys all kinds of beautiful relationships and emotions between people.

\section{CONCLUSION}

Through the above comparison of data, it is found that the chocolate packaging colors of the three brands: Dove, Hershey and Jindi, are highly compatible with their positioning. The audiences of Dove tend to be young whitecollar women, and the color is romantic and emotional. The audiences of Hershey brand are mainly the energetic children, so the packaging color is bright and jumping with more vitality. The audience of Jindi brand tends to be family and thus the color used is warm. The chocolate brands in these three brands have a clear target market and have chosen a targeted packaging color.

When pursuing change, chocolate packaging color should pay more attention to the continuous consolidation of brand image. No matter how the product changes, its brand image, product visual image, and brand promotion, etc. should always be unified, so that consumers will not be confused. The unique artistic charm has greatly stimulated the purchasing desire of the intrinsic consumer groups and potential consumers, and contributed to the final completion of consumption.

\section{REFERENCES}

[1] Zhang Wan. The Impact of Consumer Psychology on Food Packaging Design [D]. Kaifeng: Henan University, 2013. 张婉. 消费心理对食 品包装设计的影响[D]. 开封: 河南大学, 2013.

[2] Ding Wenjing. Discussion on the Humanization of Packaging Color Design [J]. China Packaging Industry, 2014, 12: 47. 丁文静.包装色 彩设计的人性化探讨[J].中国包装工业,2014,12:47 